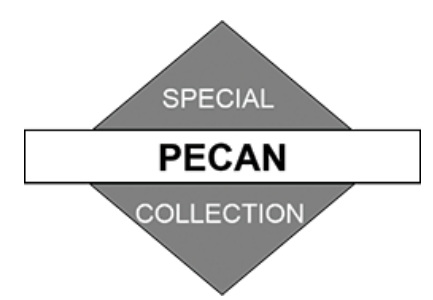

\title{
NOCTURNAL CONVECTION INITIATION DURING PECAN 2015
}

Tammy M. Weckwerth, John Hanesiak, James W. Wilson, Stanley B. Trier, Samuel K. Degelia, William A. Gallus Jr., Rita D. Roberts, and Xuguang Wang

Conceptual models of nocturnal convection initiation $(\mathrm{NCl})$ are used to summarize past knowledge and new discoveries following the Plains Elevated Convection at Night (PECAN) field campaign.

$\mathrm{T}$ horough understanding and accurate forecasting of the timing and location of U.S. Great Plains nocturnal convection initiation (NCI) remains a challenging goal. A primary reason is that $\mathrm{NCI}$ is often elevated with its source air from 900 to $600 \mathrm{hPa}$ (e.g., Wilson and Roberts 2006) and typical observing systems do not observe temperature, moisture, or wind conditions at this height with adequate temporal and spatial resolutions. To improve the understanding and forecast skill of NCI, the Plains Elevated Convection at Night (PECAN; Geerts et al. 2017) field campaign included NCI as a primary scientific objective.
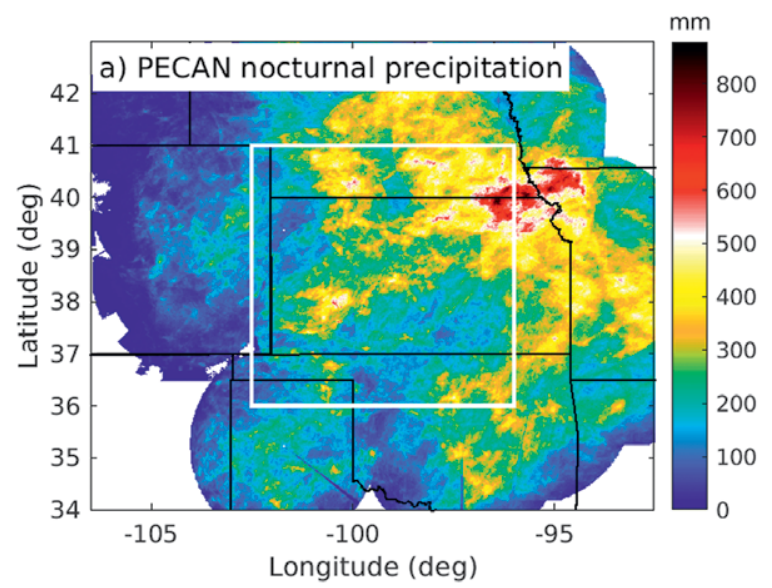

This manuscript brings together past NCI research with data from PECAN to document frequencies and forcing mechanisms of different NCI categories.

While the impact of NCI in the U.S. Great Plains is high, the forecasting skill remains relatively low. A 20-yr radar climatology illustrated that NCI events can produce hail, high winds, flooding, and in some cases, tornadoes (Reif and Bluestein 2017, hereafter RB17; Reif and Bluestein 2018). Figure 1 illustrates that locally forced NCI episodes contributed up to $30 \%-60 \%$ of the PECAN nocturnal accumulated rainfall derived from radar (Weckwerth

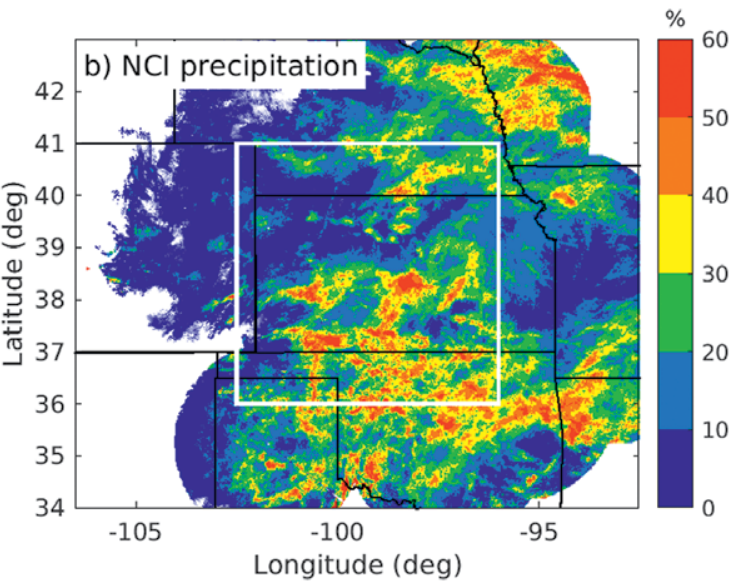

FIG. I. (a) Accumulated nocturnal precipitation (0100-1300 UTC) derived from radar data (mm) from 23 May until 22 Jul 2015 (Fig. 7b from Weckwerth and Romatschke 2019). (b) Percentage of (a) attributed to $\mathrm{NCl}$ episodes that initiated locally in the Great Plains. The white rectangle is the PECAN domain. 
and Romatschke 2019). This sizable contribution of NCI to Great Plains precipitation is consistent with previous results (Carbone and Tuttle 2008). Stelten and Gallus (2017, hereafter SG17) showed the challenges in forecasting skill by examining five different convection-allowing models. They found that the probability of detection (POD) for NCI events varied from $39 \%$ to $64 \%$ with variations in false alarm ratios (FAR) of 49\%-65\%. Spatial and temporal variability and errors in convection-allowing models occur in forecasts of both daytime convection initiation (CI) and NCI (e.g., Kain et al. 2013; Burghardt et al. 2014; Pinto et al. 2015; SG17).

Weckwerth and Parsons (2006) noted that warmseason daytime $\mathrm{CI}$ is often preceded by surface-based, boundary layer convergence zones that are apparent as radar fine lines (e.g., Wilson and Schreiber 1986) and as lines of small cumulus on visible satellite imagery (e.g., Purdom 1982; Wilson and Mueller 1993). In contrast, at night the visible satellite imagery is useless and surface-based radar boundaries are not as common. An example of PECAN NCI that occurred with no radar-observed precursors (Fig. 2a), initiated convection within $18 \mathrm{~min}$ (Fig. 2b), and led to banded convective structures (Fig. 2c) illustrates the challenge via radar data. During the night, a shallow nocturnal stable boundary layer (SBL) often develops that is difficult to observe and can inhibit the formation of near-surface convergence zones. This happens because the SBL reduces the ability of moist convective downdrafts to penetrate to near the surface due to the reduction of negative buoyancy (e.g., Markowski

AFFILIATIONS: WECKWERTH-Earth Observing Laboratory, National Center for Atmospheric Research, Boulder, Colorado; HANESIAK - University of Manitoba, Winnipeg, Manitoba, Canada; WILSON-Earth Observing Laboratory and Research Applications Laboratory, National Center for Atmospheric Research, Boulder, Colorado; TrIer-Mesoscale and Microscale Meteorology Laboratory, National Center for Atmospheric Research, Boulder, Colorado; DegelIA AND WANG_-University of Oklahoma,

Norman, Oklahoma; GalLus-lowa State University, Ames, lowa; ROBERTS-Research Applications Laboratory, National Center for Atmospheric Research, Boulder, Colorado CORRESPONDING AUTHOR: Tammy M. Weckwerth, tammy@ucar.edu

The abstract for this article can be found in this issue, following the table of contents.

DOI:10.II75/BAMS-D-18-0299.I

In final form 22 July 2019

(C)2019 American Meteorological Society

For information regarding reuse of this content and general copyright

information, consult the AMS Copyright Policy. and Richardson 2010). Elevated convection will result when the most unstable air is above an SBL (e.g., Corfidi et al. 2008; Blake et al. 2017), which typically occurs at night. The SBL and elevated unstable air are difficult to monitor with standard observations.

In addition to the SBL, a second feature important for understanding both the initiation and maintenance of nocturnal convection in the Great Plains is the low-level jet (LLJ; e.g., Pitchford and London 1962; Maddox 1983; Astling et al. 1985; Trier and Parsons 1993; Trier et al. 2006; Tuttle and Davis 2006). The LLJ is a relatively shallow wind speed maximum that occurs between 300 and $1000 \mathrm{~m}$ above ground level (AGL), appearing shortly after sunset in the warm season and reaching maximum intensity between 0600 and 0800 UTC (e.g., Blackadar 1957; Bonner 1968; Mitchell et al. 1995; Song et al. 2005; Shapiro et al. 2016). Horizontal convergence along the terminus of the LLJ implies the presence of large-scale lifting, which can assist in NCI (e.g., Tuttle and Davis 2006). Additionally, the LLJ provides an efficient means for upward and northward transport of moisture that is important for the initiation and evolution of deep, moist convection in the region (e.g., Higgins et al. 1997).

Previous recent field campaigns in the U.S. Great Plains deployed instruments to study daytime CI and deep convection. The International $\mathrm{H}_{2} \mathrm{O}$ Project (IHOP_2002; Weckwerth et al. 2004) used radars and multiple water vapor sensors to study daytime CI. The Bow Echo and Mesoscale Convective Vortex Experiment (BAMEX; Davis et al. 2004) deployed aircraft, mobile radars, and radiosondes to study mature convective systems but not NCI. The Mesoscale Predictability Experiment (MPEX; Weisman et al. 2015) used targeted dropsondes and radiosondes to study high-impact weather events but not specifically NCI. PECAN instrumentation targeted NCI by including over 100 different ground-based and airborne instruments and a unique array of PECAN Integrated Sounding Arrays (PISAs) to sample the vertical profiles of lower-tropospheric winds, temperature, and water vapor. These PISAs and the scanning radars and lidars of PECAN were used to sample the specific features (e.g., LLJ, bores, and gravity waves) and atmospheric regions (e.g., SBL and lower troposphere) relevant to better understanding of NCI.

This manuscript brings together past NCI work and PECAN data to document frequencies of different NCI types, as categorized by different structural characteristics in PECAN radar composites. This article also summarizes current knowledge of physical processes and likely forcing mechanisms associated with 
each of these NCI types using simplified conceptual models. To determine whether certain types of NCI are more predictable, a preliminary assessment is presented of the capability of a convection-allowing ensemble model in forecasting these PECAN NCI events.

METHODOLOGY. PECAN was conducted during 1 June-16 July 2015 and was geographically centered around Hays, Kansas (Geerts et al. 2017). The NCI events examined in this study occurred within the PECAN domain delineated by the rectangular region in Fig. 1.

Identification of $\mathrm{NCl}$ events. This study used the 3D regional mosaic of $0.5^{\circ}$-elevation-angle radar data (Earth Observing Laboratory 2016a) produced for PECAN to identify the NCI events. The regional radar mosaic included data from both the national network of WSR-88Ds located in the central Great Plains and NCAR's S-Pol radar (Earth Observing Laboratory 2016b; Hubbert et al. 2018) located near Hays during PECAN. NCI events were identified from 0000 to 1200 UTC (1900-0700 LT) during PECAN and included events that were not forecasted and nights when there were no PECAN missions. Similar to the methodology of Wilson and Roberts (2006), an $\mathrm{NCI}$ event was defined when there were at least two convective radar echoes $>40 \mathrm{dBZ}$ occurring near each other in space $(<20 \mathrm{~km})$ and time $(<10 \mathrm{~min})$ suggesting a common forcing mechanism. An episode typically evolved from no echo to its maximum number of echoes within $1 \mathrm{~h}$.

An LLJ was defined for this study when there were wind speeds $>15 \mathrm{~m} \mathrm{~s}^{-1}$ with a southerly component in the $0.5^{\circ}$-elevation-angle radar composite velocity field. This is comparable to the Bonner (1968) LLJ definition using radiosondes. The LLJ core was apparent as a region of confined high winds within the radar network. An example illustrating both the horizontal and vertical structure of the LLJ using

FIG. 2. S-Pol radar reflectivity data at the $0.5^{\circ}$ elevation angle from PECAN showing an example of $\mathrm{NCI}$ on I June 2015: (a) no nearby convection or boundaries or fronts apparent within the S-Pol radar data at 0609 UTC, (b) NCl at $\sim 80 \mathrm{~km}$ east of S-Pol at 0627 UTC, and (c) banded and widespread convection at 0726 UTC. Note the suggestion of wavelike structures in the blue-colored, clear-air reflectivity region to the southwest of S-Pol in (a) and the similar northeastsouthwest orientation of the resulting convective bands in (c). This case was subjectively categorized as an LLJonly $\mathrm{NCl}$ event. Range rings are $25 \mathrm{~km}$.
PECAN observations was shown in Fig. 11 of Geerts et al. (2017).

A total of $49 \mathrm{NCI}$ events were subjectively placed into five categories based on the radar-observed
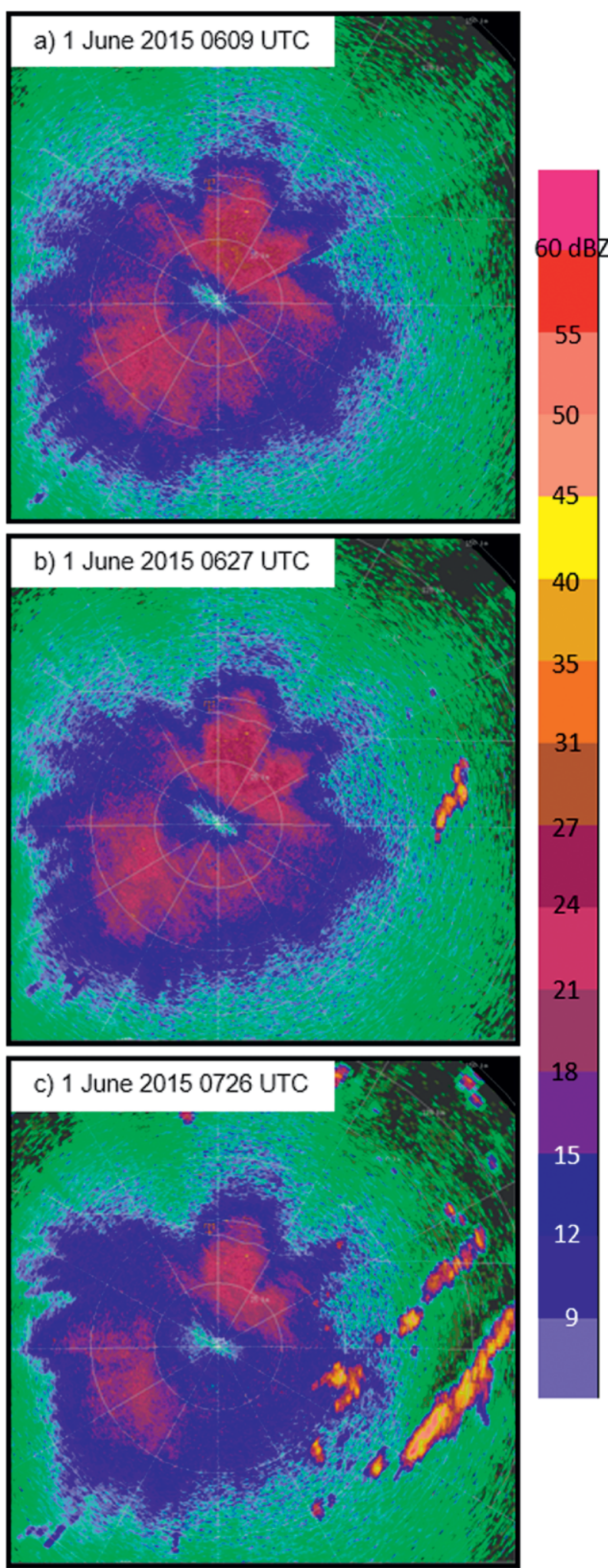
precursors (Table 1). A PECAN example of each type is shown in Fig. 3. Other analysis products (e.g., surface weather maps and surface station observations) were also used to identify possible NCI forcing features, such as fronts or convergence lines, in order to place each event in the most appropriate category. The five types of NCI events observed during PECAN are 1) NCI associated with frontal overrunning, 2) NCI associated with an LLJ (LLJ only), 3) NCI near a preexisting mesoscale convective system (MCS) or within $100 \mathrm{~km}$ of other preexisting convection, 4) NCI near a bore or density current, and 5) pristine NCI. These five types will be defined fully in the "Types of PECAN NCI events" section. The number and frequency of NCI events, along with the most similar categories of SG17, who evaluated deterministic models, are tabulated (Table 2).

Ensemble model forecasts of $\mathrm{NCl}$. During the field campaign, $\mathrm{NCI}$ events were the most challenging of the three convective forecast scenarios (i.e., MCSs, bores, NCI) for the PECAN forecasters (Geerts et al. 2017). In particular, PECAN forecasters were generally unable to pinpoint the timings and locations of $\mathrm{NCI}$ at the required lead times (i.e., $T \geq 6-48 \mathrm{~h}$ ).

The ensemble forecasts produced in real time by the University of Oklahoma (OU) Multiscale data Assimilation and Predictability (MAP) laboratory (Johnson et al. 2016) were verified for the 49 NCI events identified in Table 1 . The 20 -member,

\begin{tabular}{|c|c|c|c|}
\hline $\begin{array}{l}\text { Date (No. } \\
\text { of events) }\end{array}$ & Time (UTC) & NCl type & $\begin{array}{l}\text { LLJ (maximum velocity; } \\
\text { orientation; CI location) }\end{array}$ \\
\hline I Jun (I) & $0730-0830$ & LLJ only & 23; 150-190; middle east \\
\hline 2 Jun (I) & 0854 & LLJ only & 20; 165-200; east \\
\hline 2 Jun (I) & 1024 & Bore/density current & 20; 165-200; east \\
\hline 3 Jun (I) & 0700 & Bore/density current & $23 ; 180-210$; overrunning \\
\hline 5 Jun (I) & 0612 & Near MCS & $25 ; 180-200 ;$ middle/overrunning \\
\hline 5 Jun (3) & $0324-0936$ & Frontal overrunning & $22-25 ; 180-200$; overrunning \\
\hline 5 Jun (2) & $0648-0812$ & Bore/density current & 22; 180-200; middle/overrunning \\
\hline 6 Jun (I) & 0424 & Near MCS & $22 ; 160-180 ;$ middle east \\
\hline 7 Jun (I) & 0618 & Bore/density current & 20; 180-210; middle/overrunning \\
\hline 13 Jun (3) & $0424-0948$ & Near MCS & - \\
\hline 14 Jun (3) & $0618-0942$ & Pristine & - \\
\hline 19 Jun (2) & $0636-0736$ & Pristine & - \\
\hline 24 Jun (2) & 0612 & Frontal overrunning & 26; 190-210; overrunning \\
\hline 26 Jun (2) & $0300-0436$ & Frontal overrunning & - \\
\hline 30 Jun $(I)$ & 0906 & Pristine & - \\
\hline 2 Jul (I) & 1018 & Pristine & - \\
\hline 3 Jul (I) & 0500 & Bore/density current & - \\
\hline $4 \mathrm{Jul} \mathrm{(I)}$ & 0506 & Pristine & - \\
\hline $5 \mathrm{Jul} \mathrm{(3)}$ & $0430-0730$ & LLJ only & 22; 150-180; middle west \\
\hline $6 \mathrm{Jul}(\mathrm{I})$ & 0700 & Bore/density current & 25; 180-200; overrunning \\
\hline 9 Jul (2) & $0524-0754$ & Near MCS ( $T$ initiation) & - \\
\hline 10 Jul (4) & $0412-0842$ & Near MCS (one T initiation) & 19; 150-180; east \\
\hline II Jul (I) & 0600 & Near MCS (bow and arrow) & 24; 180-210; west \\
\hline I4 Jul (I) & $0736-1130$ & Bore/density current & - \\
\hline I5 Jul (3) & $0836-1036$ & Bore/density current & 15; 130-150; overrunning \\
\hline 16 Jul (5) & $0406-0506$ & Near MCS & - \\
\hline I6 Jul (I) & 0424 & Bore/density current & - \\
\hline
\end{tabular}


convection-permitting ensemble forecasts at a $4-\mathrm{km}$ horizontal grid spacing were initialized daily at 1300 UTC using the Advanced Research version of WRF (ARW), version 3.6.1. The details of the configuration of the real-time system, data assimilation and its evaluation can be found in Johnson et al. (2017) and Johnson and Wang (2017).

The OU MAP verification method for the NCI event at 0300 UTC 26 June 2015 is illustrated in Fig. 4. To use an objective method to verify the 49 observed NCI events, the observed composite reflectivity data were interpolated onto the $4-\mathrm{km}$ model grid (Fig. 4a). Each grid point was assigned a binary value based on whether a reflectivity echo $>40 \mathrm{dBZ}$ was observed within a radius of $96 \mathrm{~km}$ $1 \mathrm{~h}$ earlier. This radius was used following Johnson et al. (2017) and was based on subjective evaluation to identify new convection in meso-beta-scale regions. If no prior convective echoes were observed within the search radius, the convection of interest was assumed to be a new echo and was identified as NCI. This analysis was performed for the 49 observed NCI cases of Table 1 and the analysis captured 41 events. After an NCI event was observed, a rectangle was subjectively drawn around the radar echoes to constitute an event for subsequent verification of ensemble forecasts, similar to the approach used in Kain et al. (2013). This technique allowed for some location error in the forecast evaluation. If an ensemble forecast member predicted NCI within the verification rectangle, it was determined to be a successful forecast (Fig. 4d). In this example, the ensemble member was counted as a successful forecast with a +2 -h time error. To summarize the verification results, POD was
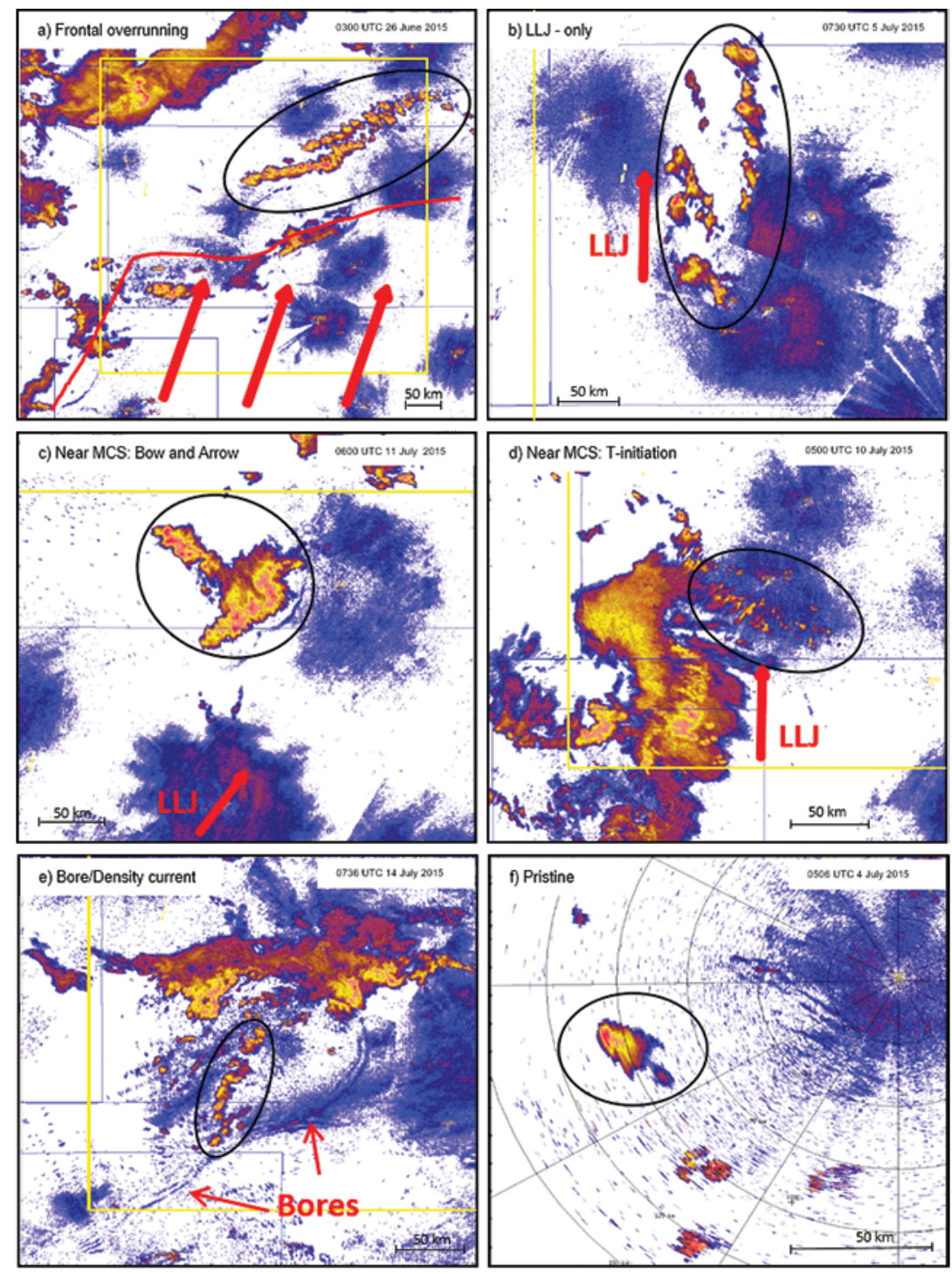

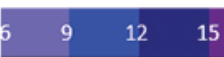

40

4550

FIG. 3. Radar reflectivity data from PECAN showing different types of $\mathrm{NCI}$. (a) Frontal overrunning at 0300 UTC 26 Jun 2015. Approximate surface frontal location is shown by red line. Multiple red arrows indicate strong southsouthwesterly flow. (b) LLJ-only initiation at 0730 UTC 5 Jul 2015. (c) Near an MCS, specifically bow-and-arrow initiation at 0600 UTC II Jul 2015. (d) Near an MCS, specifically T initiation at 0500 UTC 10 Jul 2015. (e) Near a bore/ density current at 0736 UTC 14 Jul 2015. Two bore locations are indicated. (f) Pristine NCl at 0506 UTC 4 Jul 20I5. In all panels, the black outlines indicate the region associated with the indicated type of $\mathrm{NCl}$. The length scale is shown in each panel to acknowledge different magnifications. For examples with an LLJ, the thick red arrow represents the approximate LLJ-core location and direction. The PECAN domain is shown as the yellow rectangle or yellow lines when the scale is wide enough to illustrate it. 
calculated as the percentage of ensemble members indicating NCI for that event within $2 \mathrm{~h}$ (Table 3 ). Temporal root-mean-square errors (RMSEs) were calculated for each of the $41 \mathrm{NCI}$ events. Location errors were not investigated.

TYPES OF PECAN NCI EVENTS. The following definitions describe the observations that led to the classifications of the NCI types observed in PECAN and tabulated in Table 1. It is likely that other factors influenced NCI in these cases; however, the classifications are based on the dominant structures observed within the PECAN radar network. The remainder of the "Types of PECAN NCI events" section provides details for each NCI type.

1) Frontal overrunning: An NCI event in this category was the result of near-surface air being lifted over a frontal boundary. Such events occurred with an LLJ or strong southerly lowlevel winds. The storms were observed to initiate $100-300 \mathrm{~km}$ from the front and on the cold side (typically north) of the surface boundary. The storms collectively initiated parallel to the frontal boundary with an east-west orientation. A frontal overrunning example from PECAN is shown for 0300 UTC 26 June 2015 (Fig. 3a).

2) LLJ only: An NCI event in this category had an LLJ and 1) occurred more than $100 \mathrm{~km}$ from existing storms and low-level boundaries and 2) did not have a frontal boundary. The storms formed with a north-south orientation (RB17; Gebauer et al. 2018). An example of this type of NCI is shown for 0730 UTC 5 July 2015 (Fig. 3b).

3) Near an MCS: An NCI event in this category occurred within $\sim 100 \mathrm{~km}$ of an existing MCS. The initiation was either in front of, behind, or alongside the MCS. It was not necessary that the preexisting storms formally met specific criteria of an MCS definition; it was only necessary that there was an extensive area of nearby convective storm activity. A PECAN example of "bow and arrow" (Keene and Schumacher 2013) NCI behind an MCS occurred at 0600 UTC 11 July 2015 (Fig. 3c). An example of
NCI located in advance of an MCS, called "T initiation," occurred at 0500 UTC 10 July 2015 (Fig. 3d).

4) Bore/density current: An NCI event in this category was triggered by a radar-observed bore, density current, or bore/density current combination. The initiation occurred within close proximity to the bore/density current. An example from PECAN is shown at 0736 UTC 14 July 2015 (Fig. 3e).

5) Pristine: An NCI event in this category occurred $>100 \mathrm{~km}$ from any existing storms with no evidence of a boundary layer convergence zone, front, bore, density current, or LLJ that could have triggered the initiation. An example of pristine NCI during PECAN is shown at 0506 UTC 4 July 2015 (Fig. 3f).

Frontal overrunning. Frontal overrunning, most commonly occurring with an LLJ, has been shown to initiate storms well downstream of the surface front (e.g., Colman 1990a,b; Trier and Parsons 1993; Rochette and Moore 1996; Moore et al. 2003; Horgan et al. 2007). RB17 illustrated that $35 \%$ of NCI events occurred on the cold side of mesoscale surface boundaries in their 20 -yr climatological study and this was observed $21 \%$ of the time in SG17. These types of events occurred seven times (17\% of the time within the PECAN domain) on three separate nights during PECAN (Tables 1 and 2). This was the type best captured by the OU MAP ensemble and had a POD of $63 \%$ (Table 3). One of the PECAN nights in this category (26 June) had southerly winds overrunning a front that were not strong enough to be classified as an LLJ; however, all other events in this category occurred with an LLJ. In these seven frontal overrunning cases listed in Table 1, LLJ wind maxima
TABLE 2. Number of the different types of $\mathrm{NCl}$ events observed during PECAN and the percentage frequency of occurrence in this study and in SGI7.

\begin{tabular}{|lcccc|}
\hline NCl type & $\begin{array}{c}\text { No. of } \\
\text { events }\end{array}$ & $\begin{array}{c}\text { Proportion } \\
\text { of total (\%) }\end{array}$ & $\begin{array}{c}\text { SGI7 No. of } \\
\text { events }\end{array}$ & $\begin{array}{c}\text { SGI7 } \\
\text { proportion of } \\
\text { total (\%) }\end{array}$ \\
\hline $\begin{array}{l}\text { Frontal } \\
\text { overrunning }\end{array}$ & 7 & 14 & 60 & 21 \\
\hline LLJ only & 5 & 10 & 153 & 54 \\
\hline Near MCS & 17 & 35 & 26 & 9 \\
\hline $\begin{array}{l}\text { Bore/density } \\
\text { current }\end{array}$ & 12 & 25 & - & - \\
\hline Pristine & 8 & 16 & 47 & 16 \\
\hline Total & 49 & 100 & 286 & 100 \\
\hline
\end{tabular}


were $22-26 \mathrm{~m} \mathrm{~s}^{-1}$ from $180^{\circ}$ to $190^{\circ}$ at the lowest LLJ heights near $100 \mathrm{~m} \mathrm{AGL}$ and veered to $200^{\circ}-210^{\circ}$ at $2 \mathrm{~km}$ AGL.

A conceptual model of NCI associated with frontal overrunning is shown as a south-southwest-northnortheast vertical cross section in Fig. 5, closely following that of Moore et al. (2003). The primary feature associated with frontal overrunning NCI events involves strong southerly flow [shown as an LLJ in Moore et al. (2003)] advecting relatively warm, moist air northward along or above the upward-sloping cool frontal surface. With the PECAN NCI cases, this flow always had a southerly component but did not always meet the definition of an LLJ, in contrast to the Moore et al. (2003) schematic model. In some cases, the overrunning by itself may be sufficient to initiate convection. This could occur due to relative humidity increasing and convective inhibition (CIN) being eroded while the air parcels cool and transport moisture horizontally and vertically along the sloping frontal surface. The exact location of NCI varies due to differences in the slope of the frontal and isentropic surfaces and due to differences in the magnitude, orientation, and moisture content of the low-level southerly flow (Moore et al. 2003; Peters et al. 2017). In some cases, this relatively large-scale overrunning ascent may be enhanced locally by direct thermal circulations (DTCs) due to lower-tropospheric frontogenesis (e.g., Augustine and Caracena 1994). Additionally, there may be deeper coupled DTCs associated with the LLJ and upperlevel jet streaks (ULJs) that sometimes play important roles in NCI (cf. Moore et al. 2003; Fig. 5).

There are several aspects of frontal-overrunning NCI environments that remain in need of further clarification. These include better quantification of what fraction of the total environmental mesoscale ascent can be directly attributed to the frontal-overrunning mechanisms and the degree to which more complicated veering wind profiles, which often occur in frontal

TABLE 3. OU MAP ensemble POD and temporal RMSE for each NCl category observed during PECAN. Due to the identification method failing for some events, the number of events for most of the $\mathbf{N C l}$ categories is slightly lower than in Table 2.

\begin{tabular}{|lccc|}
\hline NCl type & $\begin{array}{c}\text { No. of } \\
\text { events }\end{array}$ & POD (\%) & $\begin{array}{c}\text { Time } \\
\text { RMSE (h) }\end{array}$ \\
\hline $\begin{array}{l}\text { Frontal } \\
\text { overrunning }\end{array}$ & 7 & 63 & 1.01 \\
\hline LLJ only & 4 & 23 & 1.15 \\
\hline Near MCS & 14 & 71 & 1.08 \\
\hline $\begin{array}{l}\text { Bore/density } \\
\text { current }\end{array}$ & 9 & 55 & 1.15 \\
\hline Pristine & 7 & 50 & 1.15 \\
\hline Total & 41 & 58 & 1.08 \\
\hline
\end{tabular}

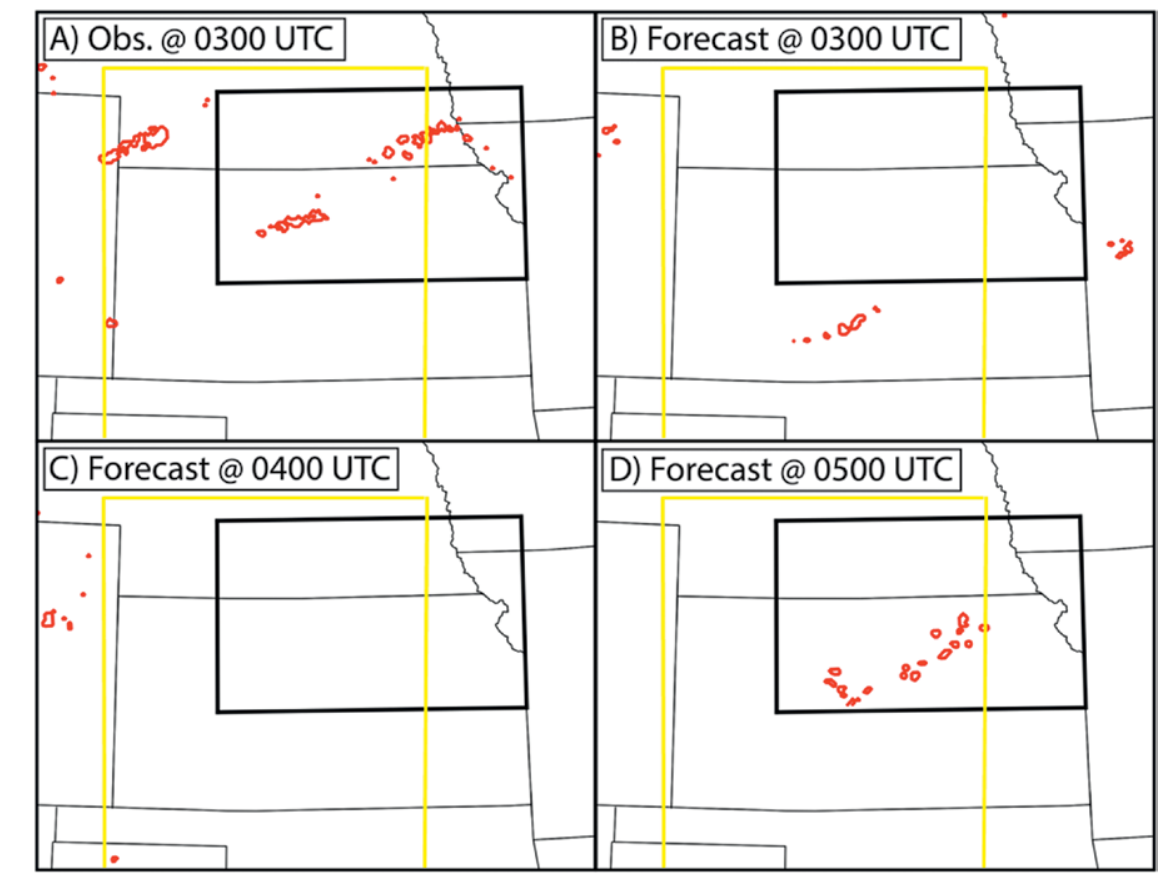

FIG. 4. Example of the OU MAP ensemble model verification technique, illustrating (a) observed and gridded composite reflectivity $>40 \mathrm{dBZ}$ at 0300 UTC 26 Jun 20I5, and simulated composite reflectivity forecasts $>40 \mathrm{dBZ}$ at (b) 0300, (c) 0400, and (d) 0500 UTC. Radar reflectivity data for this case are shown in Fig. 3a. The red contours indicate grid points where the algorithm indicated NCI. Yellow region is the PECAN domain. The black box represents the subjectively drawn rectangle over which the ensemble forecasts of $\mathrm{NCI}$ in (b)-(d) were verified for this case. A forecast member would be counted as a success if any grid point within the subdomain indicated $\mathrm{NCl}$ within a 2-h time window. This example ensemble member in (b)-(d) would be counted as a success with a $+2-h$ time error. 
environments with warm advection, influence the vertical motion.

LLJ only. LLJ-only NCI events occurred with no surface boundary but with a well-defined LLJ as a key contributor to the NCI. RB17 classified this as no-boundary CI and this type accounted for $24 \%$ of their NCI events over the Great Plains, occurring most often around 0900 UTC. SG17 found that their type 2 NCI with an LLJ occurred more frequently ( $54 \%$ of their events). However, this mechanism contributed only five NCI events (10\%) during PECAN on three separate nights between 0430 and 0854 UTC (Tables 1, 2). The difference in frequency of occurrence and timing for this study compared to RB17 and SG17 is hypothesized to be due to the different domains analyzed and different definitions of NCI categories. In SG17 many of their type 2 events occurred just outside of the PECAN domain and therefore would not be identified as NCI events in the current study. Herein, the LLJ maxima were $20-23 \mathrm{~m} \mathrm{~s}^{-1}$ from $150^{\circ}$ to $165^{\circ}$ at $100 \mathrm{~m} \mathrm{AGL}$, veering to $180^{\circ}-200^{\circ}$ at $2 \mathrm{~km}$ AGL. The NCI events occurred primarily on the eastern side of the LLJ core (Table 1). These events were not readily captured by the OU MAP ensembles and had a POD of $23 \%$ (Table 3 ).

Figure 6 is a conceptual model predominantly based on a recent PECAN study of NCI with an LLJ only and no other observed features, such as surface boundaries, fronts, bores, or ongoing convection (Gebauer et al. 2018). In the west-east cross section of Fig. 6, a veering, horizontally heterogeneous LLJ results in an elevated convergence region along its eastern edge. The veering of the LLJ also results in differential moisture advection across its axis, which, especially when combined with various mechanisms of mesoscale ascent (e.g., Trier et al. 2017; Shapiro et al. 2018), can lead to significant increases in relative humidity at the top eastern edge of the LLJ core (Gebauer et al. 2018). The effect of persistent mesoscale ascent manifests as weak upward displacements of lower-tropospheric isentropes near the location of elevated NCI (Fig. 6), which are associated with vertical temperature advection and local adiabatic cooling. The combination of local adiabatic cooling with vertical and horizontal transports of moisture may lead to the development of moist absolutely unstable layers (MAULs; Bryan and Fritsch 2000) that facilitate convective overturn-

ing. The heterogeneous nature of the LLJ also leads to convergence of the latitudinal (u) component of wind along the top eastern edge of the LLJ core, creating convergence and lifting where the southwesterly flow meets the southeasterly flow, thereby assisting with NCI, as illustrated schematically in Fig. 6. This effect may contribute to north-southoriented lines of convection on the eastern edge of the LLJ (RB17; Gebauer et al. 2018), similar to the example in Fig. 3b. 
Near an MCS. The most frequent type of NCI events during PECAN occurred near a preexisting MCS (Tables 1, 2). This type of initiation occurred 17 times on 7 nights, accounting for $35 \%$ of the total PECAN NCI events. The most similar category in SG17 was T initiation, which is a subset of our NCI occurring near an MCS, and occurred $9 \%$ of the time in their study. For this category, it was not necessary that the preexisting storms formally met any previous MCS definition; it was only necessary that NCI occurred near an extensive area of preexisting convection. It is likely that different forcing mechanisms contribute to NCI in disparate locations alongside an MCS, including locations in front of and behind the MCS, and two such conceptual models are presented in Fig. 7. The new NCI did not always have a clearly organized structure or orientation. Table 1 shows that an LLJ was observed on 4 of the 7 nights with NCI near MCSs. The LLJ core was $19-25 \mathrm{~m} \mathrm{~s}^{-1}$ with low-level winds from $150^{\circ}$ to $180^{\circ}$ at $100 \mathrm{~m}$ AGL and the $2 \mathrm{~km} \mathrm{AGL}$ winds were from $180^{\circ}$ to $210^{\circ}$. These NCI events were well captured by the OU MAP ensemble, where the POD for this category was $71 \%$ (Table 3).

One specific type of initiation near a preexisting MCS was referred to by Keene and Schumacher (2013) as the bow-and-arrow formation. Their conceptual model summarizing the key components and mechanisms contributing to this organization is reproduced in Fig. 7a. The new convection develops at the rear (west or northwest) of a preexisting MCS and is generated when the southwesterly LLJ transports heat and moisture northward behind the bow echo. This warm, moist air maintains the instability above the MCS cold pool and converges with northerly and/ or northwesterly rear inflow, generating elevated convection along the arrow region and behind the bow echo. Deformation and vertical shear along the direction of the arrow may influence the linear structure and orientation of the convection within the arrow (Keene and Schumacher 2013). This type of NCI occurred only once during PECAN on 11 July 2015, along with a south-southwesterly LLJ (Fig. 3c). The bow-and-arrow mechanism is a specific radar pattern that occurs within the more general case of rearward off-boundary development (e.g., Trier et al. 2010; Peters and Schumacher 2015, 2016).

In contrast to the bow-and-arrow type, the T-initiation type has new storm development in advance of the MCS in its direction of propagation (typically eastward). This type of NCI organization has been noted by forecasters (e.g., Johns and Hirt 1987; Przybylinski 1995) and has been reported in both observational (e.g., Smull and Augustine 1993; Marsham et al. 2011; Coniglio et al. 2011) and modeling (e.g., Trier et al. 2011) studies. The regional National Weather Service/Weather Forecast Office Science and Operations Officers (SOO) in Goodland and Dodge City, Kansas, and Hastings, Nebraska noted that $\mathrm{T}$ initiation is one of the most difficult NCI forecasting challenges (J. Martin, A. Johnson, and R. Ewald 2014, personal communication). The NCI with $\mathrm{T}$ initiation is typically elevated and occurs in regions of strong warm advection near the northern terminus of the LLJ (Fig. 7b). The T-initiation pattern 
is sometimes associated with mesoscale regions of frontogenesis (e.g., Coniglio et al. 2011). Our conceptual model (Fig. 7b) illustrates a frontogenetical environment with large-scale horizontal deformation
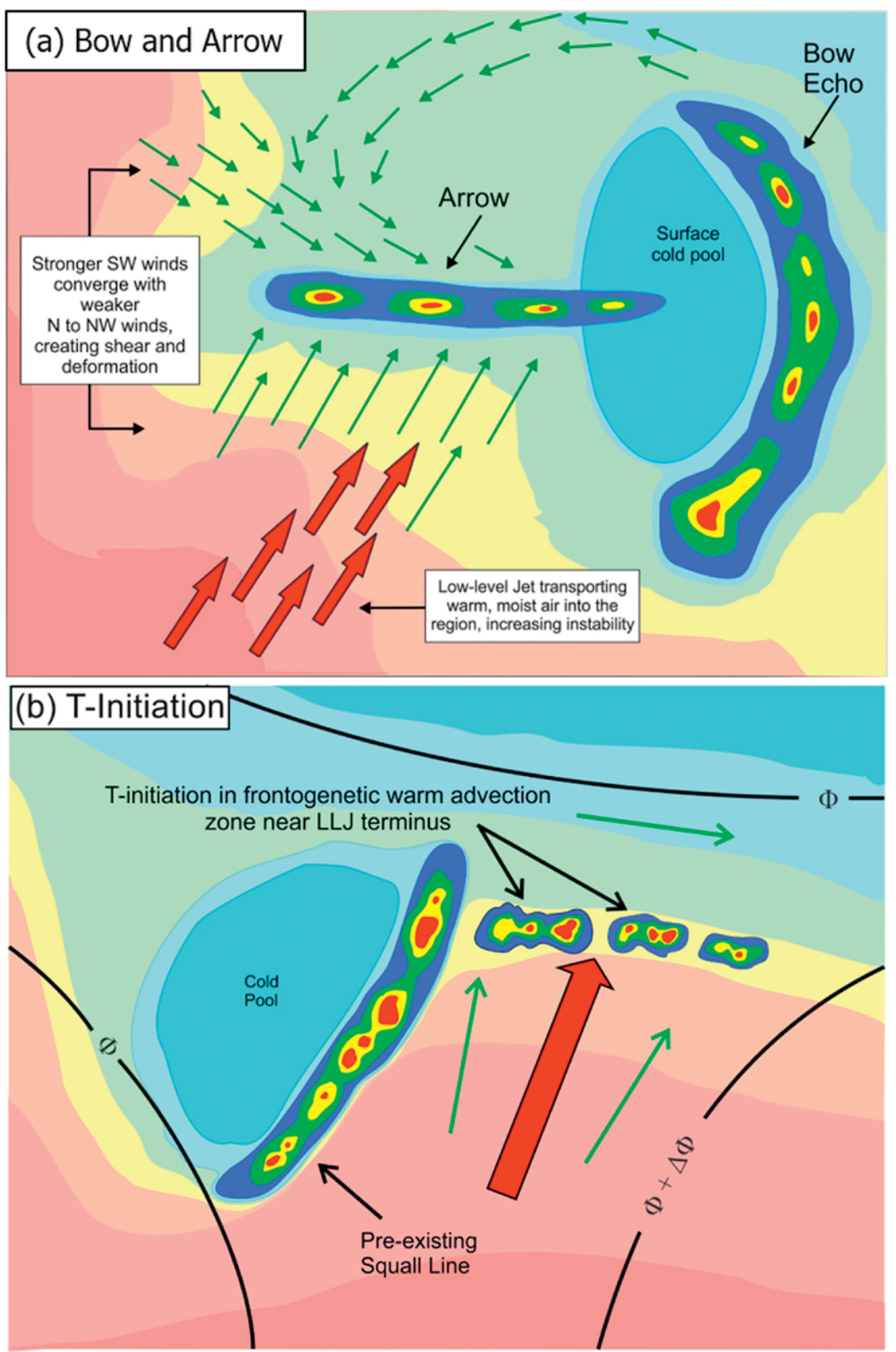

FIG. 7. Common NCl types occurring near a preexisting MCS. (a) Conceptual model of the bow-and-arrow $\mathrm{NCl}$ processes. The thick red arrows represent the LLJ, while the thin green arrows represent the wind direction and speed (longer arrows correspond to faster wind speeds). The colored contours represent isotherms where warmer (cooler) temperatures are shaded red (blue). From Keene and Schumacher (2013). (b) Conceptual model of the T-initiation $\mathrm{NCl}$ processes. Colored contours and the thick red arrow are as in part (a). The thin black lines represent contours of constant geopotential height and the thin green arrows are geostrophic wind vectors. (e.g., Augustine and Caracena 1994) often found in environments supporting $\mathrm{T}$ initiation. A similar flow pattern with significant horizontal deformation was found by Trier et al. (2017) using PECAN radiosonde observations from 10 July 2015. During this event, a brief $\mathrm{T}$ initiation within a MAUL occurred near the diagnosed ascending branch of a thermally direct mesoscale frontal circulation (Trier et al. 2017, cf. their Figs. 5, 11b, 12).

It is noteworthy that both the T-initiation and the bow-and-arrow NCI categories often exhibit aspects of mesoscale overrunning. In the case of the bow-and-arrow type, the boundary experiencing overrunning is usually an outflow boundary on the rear flank of the preexisting MCS. For the T-initiation type, it is often a larger-scale quasistationary or warm front, along which a preexisting MCS is moving, that is experiencing overrunning. It is the proximity of the new NCI to the MCS that most clearly distinguishes these cases from more generic frontal overrunning NCI cases.

Bore/density current. During PECAN, NCI events occurred 12 times (25\% of the events) near a bore or density current. The OU MAP ensemble POD for this category was $55 \%$ (Table 3 ). SG17 did not include this category because they identified only pristine events that were not generated near-surface boundaries. An LLJ occurred on 7 of the 9 nights with this type of NCI (Table 1). The LLJ core 
wind speed varied from 15 to $25 \mathrm{~m} \mathrm{~s}^{-1}$ and the winds at $100 \mathrm{~m} \mathrm{AGL}$ were from $130^{\circ}$ to $180^{\circ}$ and veered to $150^{\circ}-210^{\circ}$ at $2 \mathrm{~km}$ AGL.

Bores and density currents are similar in that they both include hydrostatic pressure jumps during their passage; however, the surface temperature typically drops with a density current and rises or remains constant for a bore. Atmospheric nocturnal bores can be induced by density currents impinging upon a stable surface layer (e.g., Crook 1988; Rottman and Simpson 1989; Koch et al. 1993; Haghi et al. 2017). Similarly, solitons or solitary waves, which are types of bores, may be produced in the same manner (e.g., Christie et al. 1979). Bores may play a role in elevated NCI and MCS maintenance (e.g., Carbone et al. 1990; Crook et al. 1990; Koch et al. 2008a,b; Marsham et al. 2011; Coleman and Knupp 2011; Grasmick et al. 2018; Parsons et al. 2019; Haghi et al. 2019).

Figure 8 shows a conceptual model for bore/density current-generated NCI based on several previous bore studies (e.g., Haghi et al. 2017; Parsons et al. 2019). The bore usually progresses at a faster pace than the parent density current. Atmospheric bores are associated with a semipermanent lifting of the SBL depth, thereby causing cooling and moistening aloft (e.g., Knupp 2006; Koch et al. 2008a,b; Parker 2008; French and Parker 2010; Browning et al. 2010), decreasing the height of the level of free convection (LFC) and reducing CIN (Parsons et al. 2019; Loveless et al. 2019). This decrease in stability occurring in association with bores may allow for elevated NCI and MCS maintenance. Our conceptual model shows an example of an undular bore (e.g., Haghi et al. 2017). In this case, air parcels are successively lifted to their maximum height along the wave crests. The uppermost elevated parcel (marked as 3) experiences the deepest lift relative to the prebore parcel height (shown by thick black up arrows) and eventually reaches the LFC while parcels 1 and 2 remain within the stable layer. With a supercritical bore or

nonundular bore [as shown in Fig. 4 of Haghi et al. (2017)], there is one primary wave crest that may influence NCI and the maintenance of convection (not shown). With a soliton/solitary waves type of bore (Haghi et al. 2017), the first wave crest exhibits the highest amplitude and may aid NCI and MCS maintenance at the leading wave crest (not shown).

Pristine NCl. There is no well-recognized unique definition of pristine CI. RB17 defined pristine $\mathrm{CI}$ as new convection not influenced by other neighboring convection and specified it as occurring $>3 \mathrm{~h}$ and $>100 \mathrm{~km}$ from other convection. SG17 defined pristine $\mathrm{CI}$ as that which was not a direct result of preexisting convection (e.g., forced by outflow boundaries). Herein, we define pristine NCI as a new convective echo $>40 \mathrm{dBZ}$ occurring more than $100 \mathrm{~km}$ from existing storms. We further require the NCI to not be associated with any precursor near-surface convergence zone, to not be occurring with an LLJ, and to not be initiated by a bore or gust front. Such pristine NCI was observed eight times (16\%) during PECAN on five nights (Tables 1 and 2). It was also identified $16 \%$ of the time in SG17. The OU MAP ensemble had a $50 \%$ POD for these events (Table 3).

Figure 9 depicts a conceptual model of pristine NCI, following Wilson et al. (2018). Elevated convergence is associated with weak, persistent mesoscale 


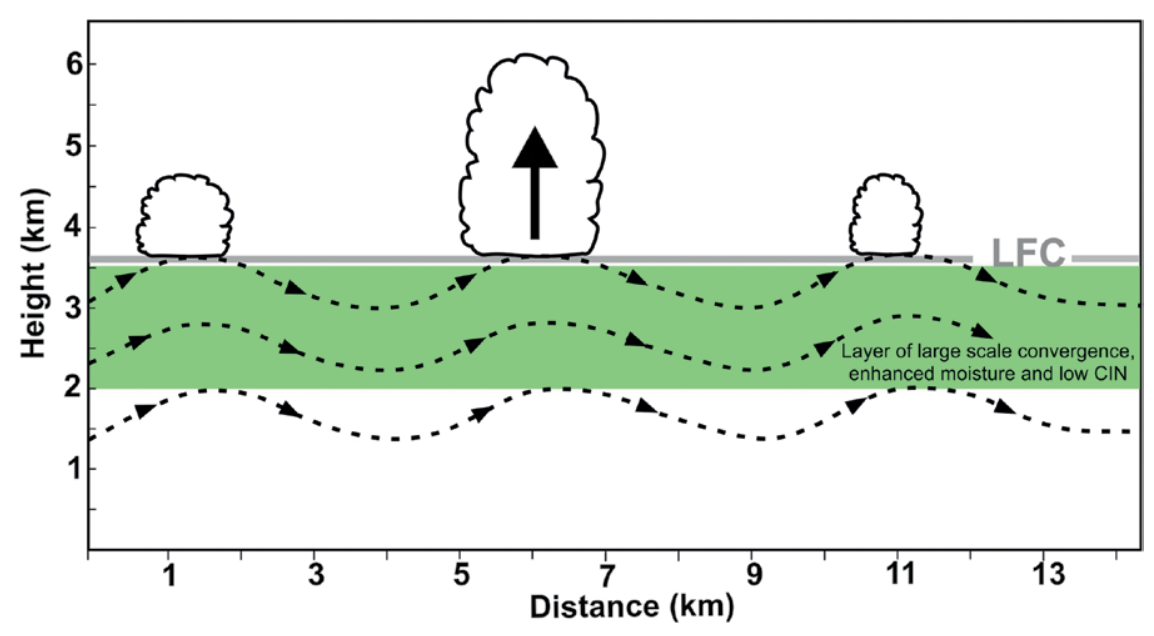

Fig. 9. Conceptual model vertical cross section illustrating possible pristine $\mathrm{NCl}$ processes. Green shaded region shows large-scale layer of enhanced moisture, elevated convergence, and low CIN. Undulations in the streamlines indicate elevated gravity waves, which is a proposed mechanism for $\mathrm{Cl}$ in the primary example case upon which this conceptual model is based. $\mathrm{NCI}$ (indicated by the cloud with a black arrow) can take place where the optimal combination of convergence, moisture, and updraft occur. Following Wilson et al. (2018).

ascent leading to an elevated layer of enhanced moisture that supports increases in the CAPE and decreases in both the CIN and the LFC height for air parcels originating above the surface. This mesoscale lifting in the environment may combine with stronger and more localized lifting caused by lower-tropospheric gravity waves leading to NCI in this conceptual model (Wilson et al. 2018). Banacos and Schultz (2005) and Wilson and Roberts (2006) also noted midlevel convergence and thermodynamic instability as major influences for initiating pristine nocturnal elevated storms during IHOP_2002.

SUMMARY AND OUTLOOK. This article summarizes the different categories of the $49 \mathrm{NCI}$ events that occurred during the PECAN field campaign. We have added to previous observational climatological studies (i.e., RB17) and model-based PECAN studies (i.e., SG17) of NCI by presenting conceptual models of the different categories of NCI. These PECAN NCI cases were primarily identified using the composite network of radar data. The five different NCI types are associated with (i) frontal overrunning (14\% of the cases), (ii) the LLJ alone (10\%), (iii) an MCS or preexisting convection (35\%), (iv) a bore or density current (25\%), or (v) a nocturnal atmosphere lacking a clearly observed forcing mechanism (pristine; 16\%). We combined previous conceptual models with revised models and newly developed models to describe the primary environmental features and physical processes associated with our five broadly defined categories of NCI.

Other potential NCI mechanisms were not examined here because they were not discernible using the PECAN radar network. These include lifting and horizontal advection associated with cyclonic potential vorticity anomalies, which have been shown to be an important factor in generation and maintenance of nocturnal convection (e.g., Jirak and Cotton 2007; RB18). Another NCI mechanism is quasigeostrophicaided ascent (e.g., RB18). The mountains-plains solenoidal circulation has also been suggested to play a role in NCI (e.g., Carbone and Tuttle 2008). An additional mechanism that could contribute to NCI near a preexisting MCS is related to microphysical processes, including evaporation, sublimation, and melting, which may cool and moisten the air beneath preexisting anvils in such a way that may help initiate new convection (e.g., Knight et al. 2004; Parker and Johnson 2004). The contribution of these various processes to NCI during PECAN were not investigated because the focus of this paper was based on what could be observed with radar.

This study presents too small of a sample to establish the statistical significance of differences in the skill of forecasts for the different NCI types with the OU MAP ensemble runs. However, an initial comparison of the different NCI types illustrates some general findings. The OU MAP model's ability to forecast NCI depended upon the NCI mechanism. NCI influenced by larger-scale forcing mechanisms, including frontal overrunning and near MCS, exhibited greater forecast skill in the ensemble runs by having greater POD with smaller time errors (Table 3). This is consistent with PECAN results of SG17 and previous results from IHOP_2002 in which Wilson and Roberts (2006) noted that daytime CI was better predicted by the $10-\mathrm{km}$ Rapid Update Cycle (RUC) in environments with synoptic-scale fronts compared to smaller-scale features, such as bores or density currents. The OU MAP 4-km forecast and 
verification domains are unlikely to fully resolve $\mathrm{NCI}$ events related to bores and pristine NCI events. Previous results showed that $1-\mathrm{km}$ grid spacing and finer are necessary to fully capture the lifting properties, such as the slope of the ascent or the erosion of inhibition, resulting from bores and atmospheric waves (Johnson et al. 2017; Johnson and Wang 2019). We suggest investigating the benefits of higher-resolution simulations, particularly for the improvement of bore/ density current and pristine NCI forecasts. Together with the observational dataset from PECAN, more in-depth comparisons of the successful and unsuccessful ensemble members could provide an excellent opportunity for making improvements on the challenging NCI-forecast problem.

It remains difficult to observe the precursors that lead to NCI. While operational radar and sounding networks are useful, high-frequency profiling of the lower-tropospheric temperature, moisture and winds would be beneficial to observe the mechanisms responsible for NCI. A network of remote sensing profilers, like PISAs deployed during PECAN, have aided in recent NCI studies (e.g., Wilson et al. 2018). A nationwide network of these systems (National Research Council 2009) should have mesoscale spacings of $\sim 50 \mathrm{~km}$ to provide critical thermodynamic and wind observations to be used for enhanced understanding, for data assimilation and for improving convective weather forecast skill. A recent experiment, Land-Atmosphere Feedback Experiment (LAFE; Wulfmeyer et al. 2018) suggested that an optimal combination of observations and assimilation of thermodynamic profiles is necessary for improved understanding of the planetary boundary layer. Developments of a small network of advanced differential absorption lidars (DIALs) to measure water vapor (e.g., Spuler et al. 2015; Weckwerth et al. 2016), calibrated aerosol (Hayman and Spuler 2017) and temperature profiles (Bunn et al. 2018) and the proposed Lower Troposphere Observing System (LOTOS) may aid in providing clear-air, high-resolution measurements of low-level temperature, moisture, and wind measurements to better understand elevated NCI processes.

In the meantime, we are optimistic that the identification of large mesoscale environmental patterns and physical processes discussed in our simplified conceptual models, when considered in conjunction with output from operational NWP models, will aid forecasters in more easily identifying situations in which NCI is most likely to occur. It is also hoped that the current summary of NCI during PECAN will stimulate additional more-detailed studies that enhance understanding of processes influencing this critically important, but only partially understood, aspect of the regional hydrologic cycle of the U.S. Great Plains.

ACKNOWLEDGMENTS. The authors gratefully acknowledge all of the instrument PIs, scientists, students, and other instrument operators who participated in PECAN. Their dedication provided a rich, exciting, and unique dataset and their careful attention to detail allowed for safe field operations under difficult nighttime conditions.

The Canadian Natural Sciences and Engineering Research Council (NSERC) Discovery Grant, the NSERCfunded Changing Cold Regions Network (CCRN), and Canada Foundation for Innovation (CFI) enabled PECAN participation by the University of Manitoba. Coauthors Wang and Degelia are supported by NSF Award AGS-1359703. The OU MAP ensemble was run on the Extreme Science and Engineering Discovery Environment (XSEDE), which is supported by National Science Foundation Grant ACI-1053575. Coauthor Gallus has been supported by Grants NSF-AGS1359606 and NSFAGS1624947. A subset of the NCAR authors gratefully acknowledge partial support through the NCAR ShortTerm Explicit Prediction (STEP) program. The National Center for Atmospheric Research is sponsored by the National Science Foundation.

The authors are grateful to Patrick McCarthy (retired from the Prairie and Arctic Storm Prediction Centre, Canada) for expertly drafting the conceptual model figures. Ulrike Romatschke (NCAR/EOL) graciously created Fig. 1, following research done for a complementary publication. The authors thank Kelly Keene (NCAR/ MMM) for providing Fig. 7a. Sean Stelten (Atmospheric Science Technology) provided valuable insight toward comparing results in SG17 with this manuscript. The first author is grateful to James Pinto for numerous insightful discussions. Morris Weisman (NCAR), Dylan Reif (OU), Jim Moore (NCAR), and three anonymous reviewers provided thoughtful and helpful reviews of an earlier version of this manuscript.

\section{REFERENCES}

Astling, E. G., J. Paegle, E. Miller, and C. J. O’Brien, 1985: Boundary layer control of nocturnal convection associated with a synoptic scale system. Mon. Wea. Rev., 113, 540-552, https://doi.org/10.1175/1520 -0493(1985)113<0540:BLCONC>2.0.CO;2.

Augustine, J. A., and F. Caracena, 1994: Lowertropospheric precursors to nocturnal MCS development over the central United States. Wea. 
Forecasting, 9, 116-135, https://doi.org/10.1175/1520 -0434(1994)009<0116:LTPTNM>2.0.CO;2.

Banacos, P. C., and D. M. Schultz, 2005: The use of moisture flux convergence in forecasting convective initiation: Historical and operational perspectives. Wea. Forecasting, 20, 351-366, https://doi .org/10.1175/WAF858.1.

Blackadar, A. K., 1957: Boundary layer wind maxima and their significance for the growth of nocturnal inversions. Bull. Amer. Meteor. Soc., 38, 283-290, https://doi.org/10.1175/1520-0477-38.5.283.

Blake, B. T., D. B. Parsons, K. R. Haghi, and S. G. Castelberry, 2017: The structure, evolution, and dynamics of a nocturnal convective system simulated using the WRF-ARW model. Mon. Wea. Rev., 145, 3179-3201, https://doi.org/10.1175/MWR -D-16-0360.1.

Bonner, W. D., 1968: Climatology of the low level jet. Mon. Wea. Rev., 96, 833-850, https://doi.org /10.1175/1520-0493(1968)096<0833:COTLLJ >2.0 .CO;2.

Browning, K. A., J. H. Marsham, J. C. Nicol, F. M. Perry, B. A. White, A. M. Blyth, and S. D. Mobbs, 2010: Observations of dual slantwise circulations above a cool undercurrent in a mesoscale convective system. Quart. J. Roy. Meteor. Soc., 135, 354-373, https://doi .org/10.1002/qj.582.

Bryan, G. H., and J. M. Fritsch, 2000: Moist absolute instability: The sixth static stability state. Bull. Amer. Meteor. Soc., 81, 1207-1230, https://doi .org/10.1175/1520-0477(2000)081<1287:MAITSS $>2.3 . \mathrm{CO} ; 2$.

Bunn, C. E., K. S. Repasky, M. Hayman, R. A. Stillwell, and S. M. Spuler, 2018: Perturbative solution to the two-component atmosphere DIAL equation for improving the accuracy of the retrieved absorption coefficient. Appl. Opt., 57, 4440-4450, https://doi .org/10.1364/AO.57.004440.

Burghardt, B. J., C. Evans, and P. J. Roebber, 2014: Assessing the predictability of convection initiation in the high plains using an object-based approach. Wea. Forecasting, 29, 403-418, https://doi .org/10.1175/WAF-D-13-00089.1.

Carbone, R. E., and J. D. Tuttle, 2008: Rainfall occurrence in the U.S. warm season: The diurnal cycle. J. Climate, 21, 4132-4146, https://doi .org/10.1175/2008JCLI2275.1.

— J. W. Conway, N. A. Crook, and M. W. Moncrieff, 1990: The generation and propagation of a nocturnal squall line. Part I: Observations and implications for mesoscale predictability. Mon. Wea. Rev., 118, 26-49, https://doi.org/10.1175/1520-0493(1990)118<0026: TGAPOA $>2.0 . \mathrm{CO} ; 2$.
Christie, D. R., K. J. Muirhead, and A. L. Hales, 1979: Intrusive density flows in the lower troposphere: A source of atmospheric solitons. $J$. Geophys. Res., 84, 4959-4970, https://doi.org/10.1029 /JC084iC08p04959.

Coleman, T. A., and K. R. Knupp, 2011: Radiometer and profiler analysis of the effects of a bore and a solitary wave on the stability of the nocturnal boundary layer. Mon. Wea. Rev., 139, 211-223, https://doi .org/10.1175/2010MWR3376.1.

Colman, B. R., 1990a: Thunderstorms above frontal surfaces in environments without positive CAPE. Part I: A climatology. Mon. Wea. Rev., 118, 1103-1122, https://doi.org/10.1175/1520-0493(1990)118<1103: TAFSIE $>2.0 . C O ; 2$.

_ 1990b: Thunderstorms above frontal surfaces in environments without positive CAPE. Part II: Organization and instability mechanisms. Mon. Wea. Rev., 118, 1123-1144, https://doi.org/10.1175/1520 -0493(1990)118<1123:TAFSIE >2.0.CO;2.

Coniglio, M. C., S. F. Corfidi, and J. S. Kain, 2011: Environment and early evolution of the 8 May 2009 derecho-producing convective system. Mon. Wea. Rev., 139, 1083-1102, https://doi .org/10.1175/2010MWR3413.1.

Corfidi, S. F., S. J. Corfidi, and D. M. Schultz, 2008: Elevated convection and castellanus: Ambiguities, significance and questions. Wea. Forecasting, 23, 12801303, https://doi.org/10.1175/2008WAF2222118.1.

Crook, N. A., 1988: Trapping of low-level internal gravity waves. J. Atmos. Sci., 45, 1533-1541, https://doi .org/10.1175/1520-0469(1988)045<1533:TOLLIG $>2$ .0.CO;2.

- R. E. Carbone, M. W. Moncrieff, and J. W. Conway, 1990: The generation and propagation of a nocturnal squall line. Part II: Numerical simulations. Mon. Wea. Rev., 118, 50-65, https://doi.org/10.1175/1520 -0493(1990)118<0050:TGAPOA >2.0.CO;2.

Davis, C. A., and Coauthors, 2004: The bow echo and MCV experiment: Observations and opportunities. Bull. Amer. Meteor. Soc., 85, 1075-1093, https://doi .org/10.1175/BAMS-85-8-1075.

Earth Observing Laboratory, 2016a: Radar regional 3D mosaic (realtime) in MDV format, version 1.0. UCAR/NCAR, accessed 15 May 2017, https://doi .org/10.5065/D6BG2M6R.

— 2016b: S-Pol radar moments data in cfRadial format, version 2.0. UCAR/NCAR, accessed 15 May 2017, https://doi.org/10.5065/D6PN93VJ.

French, A. J., and M. D. Parker, 2010: The response of simulated nocturnal convective systems to a developing low-level jet. J. Atmos. Sci., 67, 3384-3408, https:// doi.org/10.1175/2010JAS3329.1. 
Gebauer, J., A. Shapiro, E. Fedorovich, and P. Klein, 2018: Convection initiation caused by heterogeneous low-level jets over the Great Plains. Mon. Wea. Rev., 146, 2615-2637, https://doi.org/10.1175/MWR -D-18-0002.1.

Geerts, B., and Coauthors, 2017: The 2015 Plains Elevated Convection At Night field project. Bull. Amer. Meteor. Soc., 98, 767-786, https://doi.org/10.1175 /BAMS-D-15-00257.1.

Grasmick, C., B. Geerts, D. D. Turner, Z. Wang, and T. M. Weckwerth, 2018: The relation between nocturnal MCS evolution and its outflow boundaries in the stable boundary layer: An observational study of the 15 July 2015 MCS in PECAN. Mon. Wea. Rev., 146, 3203-3226, https://doi.org/10.1175/MWR -D-18-0169.1.

Haghi, K. R., D. B. Parsons, and A. Shapiro, 2017: Bores observed during IHOP_2002: The relationship of bores to the nocturnal environment. Mon. Wea. Rev., 145, 3929-3946, https://doi.org/10.1175/MWR -D-16-0415.1.

— , and Coauthors, 2019: Bore-ing into nocturnal convection. Bull. Amer. Meteor. Soc., 100, 1103-1121, https://doi.org/10.1175/BAMS-D-17-0250.1.

Hayman, M., and S. Spuler, 2017: Demonstration of a diode-laser-based high spectral resolution lidar (HSRL) for quantitative profiling of clouds and aerosols. Opt. Express, 25, A1096-A1110, https://doi .org/10.1364/OE.25.0A1096.

Higgins, R. W., Y. Yao, E. S. Yarosh, J. E. Janowiak, and K. C. Mo, 1997: Influence of the Great Plains low-level jet on summertime precipitation and moisture transport over the central United States. J. Climate, 10, 481-507, https://doi.org/10.1175/1520 -0442(1997)010<0481:IOTGPL>2.0.CO;2.

Horgan, K. L., D. M. Schultz, J. E. Hales Jr., S. F. Corfidi, and R. H. Johns, 2007: A five-year climatology of elevated severe convective storms in the United States east of the Rocky Mountains. Wea. Forecasting, 22, 1031-1044, https://doi.org/10.1175/WAF1032.1.

Hubbert, J. C., J. W. Wilson, T. M. Weckwerth, S. M. Ellis, M. Dixon, and E. Loew, 2018: S-Pol's polarimetric data reveal detailed storm features (and insect behavior). Bull. Amer. Meteor. Soc., 99, 2045-2060, https://doi.org/10.1175/BAMS-D-17-0317.1.

Jirak, I. L., and W. R. Cotton, 2007: Observational analysis of the predictability of mesoscale convective systems. Wea. Forecasting, 22, 813-838, https://doi .org/10.1175/WAF1012.1.

Johns, R. H., and W. D. Hirt, 1987: Derechos: Widespread convectively induced windstorms. Wea. Forecasting, 2, 32-49, https://doi.org/10.1175/1520 -0434(1987)002<0032:DWCIW>2.0.CO;2.
Johnson, A., and X. Wang, 2017: Design and implementation of a GSI-based convection-allowing ensemble data assimilation and forecast system for the PECAN field experiment. Part I: Optimal configurations for nocturnal convection prediction using retrospective cases. Wea. Forecasting, 32, 289-315, https://doi .org/10.1175/WAF-D-16-0102.1.

— , and — 2019: Multicase assessment of the impacts of horizontal and vertical grid spacing, and turbulence closure model, on subkilometer-scale simulations of atmospheric bores during PECAN. Mon. Wea. Rev., 147, 1533-1555, https://doi.org/10.1175 /MWR-D-18-0322.1.

- - — , and S. Degelia, 2016: OU MAP WRF ARW deterministic and ensemble 2-D fields, version 1.0. UCAR/NCAR, accessed 21 November 2016, https:// doi.org/10.5065/D6125R2T.

,$- \ldots$, and — 2017: Design and implementation of a GSI-based convection-allowing ensemble-based data assimilation and forecast system for the PECAN field experiment. Part II: Overview and evaluation of a real-time system. Wea. Forecasting, 32, 1227-1251, https://doi.org/10.1175/WAF-D-16-0201.1.

Kain, J. S., and Coauthors, 2013: A feasibility study for probabilistic convection initiation forecasts based on explicit numerical guidance. Bull. Amer. Meteor. Soc., 94, 1213-1225, https://doi.org/10.1175/BAMS -D-11-00264.1.

Keene, K. M., and R. S. Schumacher, 2013: The bow and arrow mesoscale convective structure. Mon. Wea. Rev., 141, 1648-1672, https://doi.org/10.1175 /MWR-D-12-00172.1.

Knight, C. A., L. J. Miller, and W. D. Hall, 2004: Deep convection and "first echoes" within anvil precipitation. Mon. Wea. Rev., 132, 1877-1890, https://doi .org/10.1175/1520-0493(2004)132<1877:DCAFEW $>2.0 . \mathrm{CO} ; 2$.

Knupp, K. R., 2006: Observational analysis of a gust front to bore to solitary wave transition within an evolving nocturnal boundary layer. J. Atmos. Sci., 63, 2016-2035, https://doi.org/10.1175/JAS3731.1.

Koch, S. E., F. Einaudi, P. B. Dorian, and S. Lang, 1993: A mesoscale gravity-wave event observed during CCOPE. Part IV: Stability analysis and Doppler-derived wave vertical structure. Mon. Wea. Rev., 121, 2483-2510, https://doi.org/10.1175/1520 -0493(1993)121<2483:AMGWEO>2.0.CO;2.

, W. Feltz, F. Fabry, M. Pagowski, B. Geerts, K. M. Bedka, D. O. Miller, and J. W. Wilson, 2008a: Turbulent mixing processes in atmospheric bores and solitary waves deduced from profiling systems and numerical simulation. Mon. Wea. Rev., 136, 1373-1400, https://doi.org/10.1175/2007MWR2252.1. 
-, C. Flamant, J. W. Wilson, B. M. Gentry, and B. D. Jamison, 2008b: An atmospheric soliton observed with Doppler radar, differential absorption lidar, and a molecular Doppler lidar. J. Atmos. Oceanic Technol., 25, 1267-1287, https://doi .org/10.1175/2007JTECHA951.1.

Loveless, D. M., T. J. Wagner, D. D. Turner, S. A. Ackerman, and W. F. Feltz, 2019: A composite perspective on bore passages during the PECAN campaign. Mon. Wea. Rev., 147, 1395-1413, https:// doi.org/10.1175/MWR-D-18-0291.1.

Maddox, R. A., 1983: Large-scale meteorological conditions associated with midlatitude, mesoscale convective complexes. Mon. Wea. Rev., 111, 1475-1493, https://doi.org/10.1175/1520-0493(1983)111<1475: LSMCAW $>2.0 . \mathrm{CO} ; 2$.

Markowski, P., and Y. Richardson, 2010: Mesoscale Meteorology in Midlatitudes. John Wiley and Sons, 430 pp., https://doi.org/10.1002/9780470682104.

Marsham, J. H., S. B. Trier, T. M. Weckwerth, and J. W. Wilson, 2011: Observations of elevated convection initiation leading to a surface-based squall line during 13 June IHOP_2002. Mon. Wea. Rev., 139, 247-271, https://doi.org/10.1175/2010MWR3422.1.

Mitchell, M. J., R. W. Arritt, and K. Labas, 1995: A climatology of the warm season Great Plains lowlevel jet using wind profiler observations. Wea. Forecasting, 10, 576-591, https://doi.org/10.1175/1520 -0434(1995)010<0576:ACOTWS>2.0.CO;2.

Moore, J. T., F. H. Glass, C. E. Graves, S. M. Rochette, and M. J. Singer, 2003: The environment of warmseason elevated thunderstorms associated with heavy rainfall over the central United States. Wea. Forecasting, 18, 861-878, https://doi.org/10.1175/1520 -0434(2003)018<0861:TEOWET >2.0.CO;2.

National Research Council, 2009: Observing Weather and Climate from the Ground Up: A Nationwide Network of Networks. National Academies Press, 234 pp., https://doi.org/10.17226/12540.

Parker, M. D., 2008: Response of simulated squall lines to low-level cooling. J. Atmos. Sci., 65, 1323-1341, https://doi.org/10.1175/2007JAS2507.1.

—_, and R. H. Johnson, 2004: Simulated convective lines with leading precipitation. Part II: Evolution and maintenance. J. Atmos. Sci., 61, 1656-1673, https://doi.org/10.1175/1520-0469(2004)061<1656: SCLWLP $>2.0 . C O ; 2$.

Parsons, D., K. Haghi, K. Halbert, B. Elmer, and J. Wang, 2019: The potential role of atmospheric bores and gravity waves in the initiation and maintenance of nocturnal convection over the Southern Great Plains. J. Atmos. Sci., 76, 43-68, https://doi.org/10.1175 /JAS-D-17-0172.1.
Peters, J. M., and R. S. Schumacher, 2015: Mechanisms for organization and echo training in a flash-floodproducing mesoscale convective system. Mon. Wea. Rev., 143, 1058-1085, https://doi.org/10.1175/MWR -D-14-00070.1.

$\longrightarrow$, and — 2016: Dynamics governing a simulated mesoscale convective system with a training convective line. J. Atmos. Sci., 73, 2643-2664, https://doi .org/10.1175/JAS-D-15-0199.1.

—, E. R. Nielsen, M. D. Parker, A. M. Hitchcock, and R. S. Schumacher, 2017: The impact of low-level moisture errors on model forecasts of an MCS observed during PECAN. Mon. Wea. Rev., 145, 3599-3625, https://doi.org/10.1175/MWR-D-16-0296.1.

Pinto, J. O., J. A. Grim, and M. Steiner, 2015: Assessment of the high-resolution rapid refresh model's ability to predict mesoscale convective systems using objectbased evaluation. Wea. Forecasting, 30, 892-913, https://doi.org/10.1175/WAF-D-14-00118.1.

Pitchford, K. L., and J. London, 1962: The low-level jet as related to nocturnal thunderstorms over midwest United States. J. Appl. Meteor., 1, 43-47, https://doi .org/10.1175/1520-0450(1962)001<0043:TLLJAR>2 $.0 . \mathrm{CO} ; 2$.

Przybylinski, R. W., 1995: The bow echo: Observations, numerical simulations, and severe weather detection methods. Wea. Forecasting, 10, 203-218, https://doi .org/10.1175/1520-0434(1995)010<0203:TBEONS $>2.0 . \mathrm{CO} ; 2$.

Purdom, J. F. W., 1982: Subjective interpretation of geostationary satellite data for nowcasting. Nowcasting, K. A. Browning, Ed., Academic Press, 149-166.

Reif, D. W., and H. B. Bluestein, 2017: A 20-year climatology of nocturnal convection initiation over the central and southern Great Plains during the warm season. Mon. Wea. Rev., 145, 1615-1639, https://doi .org/10.1175/MWR-D-16-0340.1.

- , and - 2018: Initiation mechanisms of nocturnal convection without nearby surface boundaries over the central and southern Great Plains during the warm season. Mon. Wea. Rev., 146, 3053-3070, https://doi.org/10.1175/MWR-D-18-0040.1.

Rochette, S. M., and J. T. Moore, 1996: Initiation of an elevated mesoscale convective system associated with heavy rainfall. Wea. Forecasting, 11, 443-457, https://doi.org/10.1175/1520-0434(1996)011<0443: IOAEMC $>2.0 . \mathrm{CO} ; 2$.

Rottman, J. W., and J. E. Simpson, 1989: The formation of internal bores in the atmosphere: A laboratory model. Quart. J. Roy. Meteor. Soc., 115, 941-963, https://doi.org/10.1002/qj.49711548809.

Shapiro, A., E. Fedorovich, and S. Rahimi, 2016: A unified theory for the Great Plains nocturnal low- 
level jet. J. Atmos. Sci., 73, 3037-3057, https://doi .org/10.1175/JAS-D-15-0307.1.

$\ldots,-$, and J. G. Gebauer, 2018: Mesoscale ascent in nocturnal low-level jets. J. Atmos. Sci., 75, 1403-1427, https://doi.org/10.1175/JAS-D-17-0279.1.

Smull, B. F., and J. A. Augustine, 1993: Multiscale analysis of a mature mesoscale convective complex. Mon. Wea. Rev., 121, 103-121, https://doi.org/10.1175/1520 -0493(1993)121<0103:MAOAMM>2.0.CO;2.

Song, J., K. Liao, R. L. Coulter, and B. M. Lesht, 2005: Climatology of the low-level jet at the Southern Great Plains atmospheric boundary layer experiments site. J. Appl. Meteor., 44, 1593-1606, https:// doi.org/10.1175/JAM2294.1.

Spuler, S. M., K. S. Repasky, B. Morley, D. Moen, M. Hayman, and A. R. Nehrir, 2015: Field-deployable diode-laser-based differential absorption lidar (DIAL) for profiling water vapor. Atmos. Meas. Tech., 8, 1073-1087, https://doi.org/10.5194/amt-81073-2015.

Stelten, S., and W. A. Gallus Jr., 2017: Pristine nocturnal convective initiation: A climatology and preliminary examination of predictability. Wea. Forecasting, 32, 1613-1635, https://doi.org/10.1175 /WAF-D-16-0222.1.

Trier, S. B., and D. B. Parsons, 1993: Evolution of environmental conditions preceding the development of a nocturnal mesoscale convective complex. Mon. Wea. Rev., 121, 1078-1098, https://doi.org/10.1175/1520 -0493(1993)121<1078:EOECPT>2.0.CO;2.

—, C. A. Davis, D. A. Ahijevych, M. L. Weisman, and G. H. Bryan, 2006: Mechanisms supporting longlived episodes of propagating nocturnal convection within a 7-day WRF model simulation. J. Atmos. Sci., 63, 2437-2461, https://doi.org/10.1175/JAS3768.1.

- , - and - 2010: Environmental controls on the simulated diurnal cycle of warmseason precipitation in the continental United States. J. Atmos. Sci., 67, 1066-1090, https://doi .org/10.1175/2009JAS3247.1.

_ J. H. Marsham, C. A. Davis, and D. A. Ahijevych, 2011: Numerical simulations of the postsunrise reorganization of a nocturnal mesoscale convective system during 12 June IHOP_2002. J. Atmos. Sci., 68, 2988-3011, https://doi.org/10.1175/JAS-D-11-0112.1.

— J. W. Wilson, D. A. Ahijevych, and R. A. Sobash, 2017: Mesoscale vertical motions near nocturnal convection initiation in PECAN. Mon. Wea. Rev.,
145, 2919-2941, https://doi.org/10.1175/MWR-D $-17-0005.1$.

Tuttle, J. D., and C. A. Davis, 2006: Corridors of warm season precipitation in the central United States. Mon. Wea. Rev., 134, 2297-2317, https://doi .org/10.1175/MWR3188.1.

Weckwerth, T. M., and D. B. Parsons, 2006: A review of convection initiation and motivation for IHOP_2002. Mon. Wea. Rev., 134, 5-22, https://doi.org/10.1175 /MWR3067.1.

— - and U. Romatschke, 2019: Where, when, and why did it rain during PECAN? Mon. Wea. Rev., 147, 35573573, https://doi.org/10.1175/MWR-D-18-0458.1.

— - and Coauthors, 2004: An overview of the International $\mathrm{H}_{2} \mathrm{O}$ Project (IHOP_2002) and some preliminary highlights. Bull. Amer. Meteor. Soc., 85, 253-277, https://doi.org/10.1175/BAMS-85-2-253.

— , K. J. Weber, D. D. Turner, and S. M. Spuler, 2016: Validation of a water vapor micropulse differential absorption lidar (DIAL). J. Atmos. Oceanic Technol., 33, 2353-2372, https://doi.org/10.1175/JTECH-D-16-0119.1.

Weisman, M. L., and Coauthors, 2015: The Mesoscale Predictability Experiment (MPEX). Bull. Amer. Meteor. Soc., 96, 2127-2149, https://doi.org/10.1175 /BAMS-D-13-00281.1.

Wilson, J. W., and W. E. Schreiber, 1986: Initiation of convective storms at radar-observed boundary-layer convergence lines. Mon. Wea. Rev., 114, 2516-2536, https://doi.org/10.1175/1520-0493(1986)114<2516: IOCSAR $>2.0$. CO;2.

— , and C. K. Mueller, 1993: Nowcasts of thunderstorm initiation and evolution. Wea. Forecasting, 8, 113-131, https://doi.org/10.1175/1520-0434(1993) 008<0113:NOTIAE $>2.0 . C O ; 2$.

— , and R. D. Roberts, 2006: Summary of convective storm initiation and evolution during IHOP: Observational and modeling perspective. Mon. Wea. Rev., 134, 23-47, https://doi.org/10.1175/MWR3069.1.

, S. B. Trier, D. W. Reif, R. D. Roberts, and T. M. Weckwerth, 2018: Nocturnal elevated convection initiation of the PECAN 4 July hailstorm. Mon. Wea. Rev., 146, 243-262, https://doi.org/10.1175 /MWR-D-17-0176.1.

Wulfmeyer, V., and Coauthors, 2018: A new research approach for observing and characterizing landatmosphere feedback. Bull. Amer. Meteor. Soc., 99, 1639-1667, https://doi.org/10.1175/BAMS -D-17-0009.1. 
